\title{
On or Coming to your Campus Soon: Drones
}

\author{
Libby V. Morris ${ }^{1}$
}

Published online: 10 April 2015

(C) Springer Science+Business Media New York 2015

What do I know about drones? Very little, but I am curious about their current and future use. The official name, as I understand, is "unmanned aerial vehicles" (UAVs). Why not call them "unwomanned" aerial vehicles? I guess it is an example of the holdover of terms like "manpower" instead of "workforce" for labor analyses. Even the automatic spell checker does not recognize unwomanned. I digress, but language matters and words influence our thinking and are used to share our thoughts.

The most extensive use to-date of drones has been by the military for combat and surveillance. A primary advantage is the ability to perform high level, high-risk tasks by remote control, either via distant operators or pre-programming. Daily, national, and international news stories feature stories of governmental and military use, a topic I will avoid. Rather, I am interested in the reports of academic and civilian uses (or potential uses) for these high-tech devices.

In 2011 and 2012, journalism programs at the University of Nebraska and the University of Missouri were tapping into the adaptability of drones for civilian uses; and the institutions were designing courses to prepare students to use drones in reporting on natural disasters and other events. Imagine how this technology could be used to cover marathons, hurricanes, traffic patterns, and large outdoor events. In 2013, the FAA sent cease and desist letters to the aforementioned institutions saying that they must apply as a public entity for a certificate of authorization (COA). Evidently, the programs had operated under the regulations for model aircraft, which require staying below 400 feet, using a sight line, along with other guidelines. So, both journalism programs were put on hold in order to pursue COA certificates from the FAA to incorporate drones into their reporting programs. See $<$ http://chronicle.com/blogs/wiredcampus/ 2-drone-journalism-programs-seek-federal-approval-to-resume-flying/45653>.

The FAA regulations are too complicated to review here, but the development of regulations and plans for integration of non-governmental drones into public airspace continues (see Federal Aviation Administration website). In 2014, the FAA picked six test sites for UAVs including three universities - Texas A\&M at Corpus Christi, Virginia Tech, and the University of Alaska. Each claim a large number of additional partners, and all are excited about the pipeline to federal research dollars and associated economic development for their regions.

Libby V. Morris

lvmorris@uga.edu

1 Institute of Higher Education, University of Georgia, 102 Meigs Hall, Athens, GA 30602-6772, USA 
Those institutions are not alone in their interest and use of drones, although this name is not preferred by academics. Rather, academics and others prefer the positive connotation associated with robots, copters, or flybots.

Robotic research in higher education is not new. Lora Weiss at the Georgia Tech Research Institute has been working for more than 20 years with technologies for "unmanned and autonomous systems," <http://www.gtri.gatech.edu/news/lora-weiss-named-chief-scientistgtri>; but having "flybots" travelling in the same airspace with our helicopters, small planes, and commercial aircraft is definitely a change and a challenge. The rapidly escalating interest in the use of drones outside of robotic programs and the military, however, is driven by advances in the technology, the multitude of potential applications, the relatively low cost of the devices-a few hundred to a few thousand dollars-and the possibility for large financial gains in a sector that is projected to be worth more than a billion in the upcoming decade. Plus, the high-tech jobs will number in the thousands, and training for those jobs are our business! Colleges and universities want to be on the forefront on this high tech market - research and development, educational programs, and devising new applications.

Drones may have many useful applications, including crop management (only water and spray what is needed), firefighting (tracking the movement of firefighters and outbreaks), environmental monitoring (wildlife to streams), covering sports, and aerial photography (movies and landscapes), to name only a few. See Vala Afshar's slideshow on potential application and other useful information at <http:/www.huffingtonpost.com/vala-afshar/10uses-of-drones-in-high_b_5988758.html>. Commercial operations envision product-delivery by drones. Who has not seen the online video showing a package delivered by a drone? Should the brown truck be worried?

Colleges and universities are also using aerial photography on campuses in innovative ways. At Colgate University drones captured the class of 2018 as well as move-in day, <http:// news.colgate.edu/2014/10/colgates-experimentation-with-drones-highlighted-in-chroniclehuffington-post.html/>. The sky overhead is not the only place for drones though: a Canterbury lecturer and his colleagues deployed a drone to map ice algae in Antarctica. Sure beats swimming under the ice! The podcast can be heard here: <https:/www. insidehighered.com/audio/2015/02/17/mapping-ice-algae-underwater-drones $>$.

Safety and privacy issues are at the core of the discussions of governmental, commercial and academic uses. How will drones avoid collisions? Will information about individuals and their movement at events be tracked, kept, and shared? Who will certify and track use? In the meantime, many colleges and universities are moving ahead with programs to equip students to design, manufacture, and implement sophisticated programs for drones (especially those for civilian purposes). In early 2014, USA Today reported on drone majors at the University of Arizona, the University of North Dakota, Kansas State University Salina, and Embry Riddle Aeronautical University. See Sydney Kashiwagi's article in $<\mathrm{http} / /$ www.usatoday.com/story/ news/nation/2013/12/31/drone-technology-uav-unmanned-aircraft/3683835/>.

Yes, drones and planning for drones may be on your campus, too. I found a course listed at my institution. How about yours? For a good laugh, watch the video showing MIT's director of admissions, Stu Schmill, sending a college acceptance letter delivered by a drone. Partreality, part-simulation the spoof is quite entertaining. Kudos to the dean at MIT for his sense of humor, and at MIT no less, an institution with a long history of research and development in UAVs. See <https:/www.insidehighered.com/quicktakes/2015/03/09/mit-imaginesadmissions-acceptances-drone $>$.

Emerging educational innovation or educational hype? It may be too early to decide. 